\title{
IDENTIFICATION OF GROUNDWATER DISTRIBUTION USING SELF POTENTIAL METHOD
}

\author{
Muhammad Fathur Rouf Hasan ${ }^{1}$, Tri Widya Swastika ${ }^{2}$, Nunung Martina ${ }^{3}$, \\ Linda Sari Wulandari ${ }^{4}$ \\ 1,2,3,4, Civil Engineering, State Polytechnic of Jakarta, Depok, 16425, Indonesia \\ e-mail : rouf@sipil.pnj.ac.id
}

\begin{abstract}
The drought is one of the biggest problems for the community, this problem will be slightly resolved if the regions have a groundwater sources. This research has been carried out in the karst area, Druju Village, Sumbermanjing District, Wetan Regency, Malang. The purpose of this study is to determine the distribution of groundwater in the Wonorejo Village, Malang District. The method that used is the Self Potential (SP) method using leap frog configuration with 104 measurement points. The results of this study indicate the value of electric potential shown between 0-13.5 $\mathrm{mV}$, and assume that a low potential value $(0-1 \mathrm{mV})$ is an indication of groundwater distribution. Areas with low potential values are found in four area. The area with the lowest potential value can be used as a reference in making wells. The possibility of groundwater distribution in this research area is not in one line / flow. However, it is possible that in areas outside the research location, groundwater flow is in one lane. Thus, to prove this assumption it is necessary to carry out further research in a wider area and the use of other geophysical methods to obtain more varied subsurface information.
\end{abstract}

Keywords : Karst; Ground Water; Self Potential; Malang

\section{INTRODUCTION}

Water is one of the main needs of living things, because all living things need water for their survival. In the rainy season the presence of water can be overflow, but on the contrary in the long dry season some areas can get drought so that they will very difficult for getting water.

Generally, areas that often get drought are areas with a form of karst area as a subsurface structures. Karst area have rock geological conditions that are easily soluble and quite high of porosity, so that they can store a large amount of water reserves (Ford \& Williams, 2007). The karst region has an underground river aquifer system where underground rivers originate from the water currents on the surface that are lost because water enters the ground by seeping through cracks in the incoming limestone according to the underground slope so that it becomes underground water flow (Fetter, 1994 ). This causes the karst area to be difficult to get water in the surface, but in the depths of the karst region it has the potential of underground rivers.

Based on the disaster inventory data from the Malang District Disaster Management Agency (BPBD) in 2015 that Sumbermanjing Wetan Sub-district at Malang Regency included droughtstricken areas throughout OctoberNovember 2015 (Malang District Disaster Management Agency, 2015). If the geological map of the turen sheet shown in Figure 1 is reviewed, the surface area of the research is included of the Deposite of Volcanic Formation which is composed of Coarse-Fine Tuffs, Pumice and Andesitic Fragments. While the lower part is a wonosari formation which is composed of 
limestone, sandy marl and claystone intercalations. (Sujanto et al., 1992).

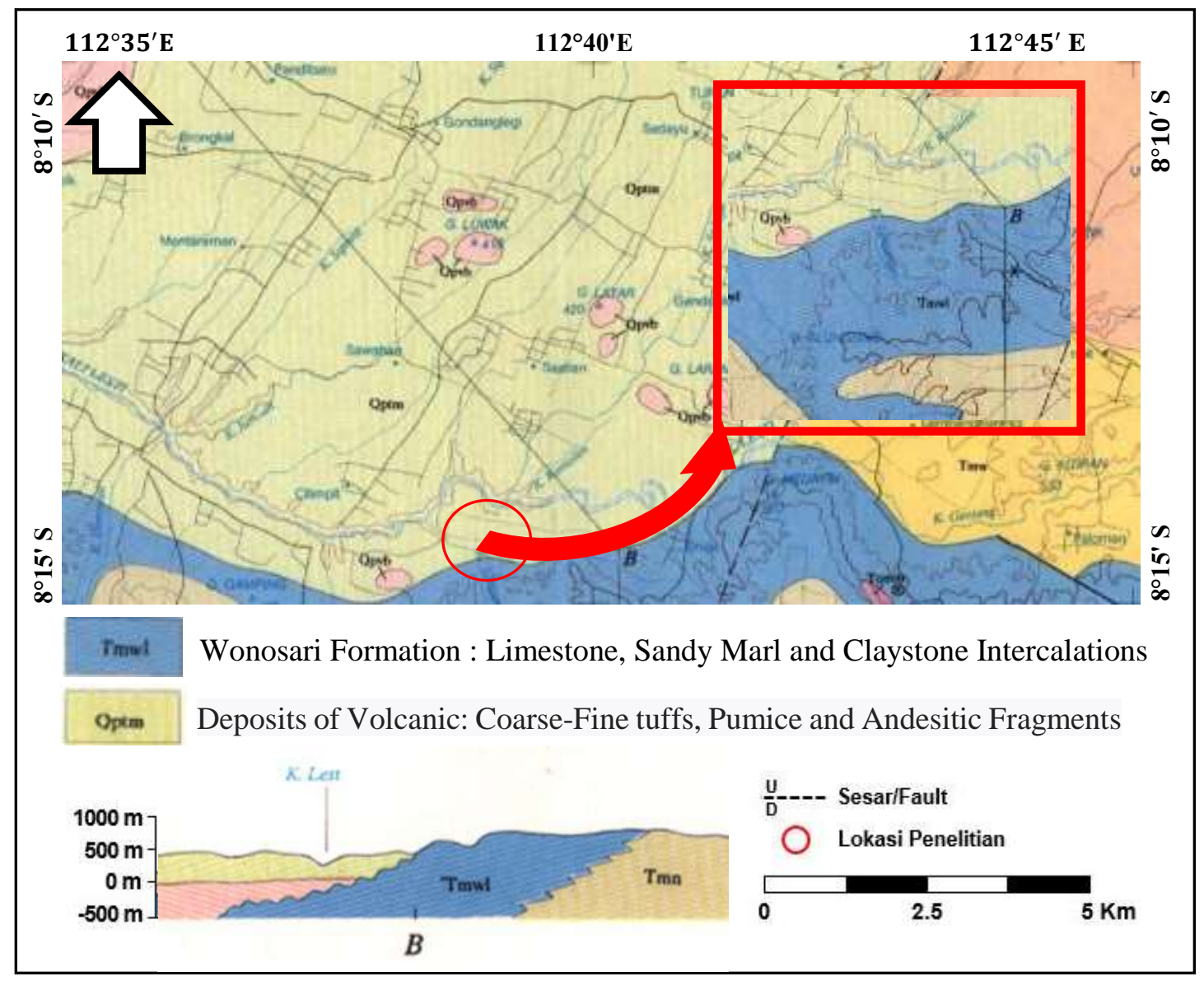

Figure 1. Regional Geological Maps of Research Sites (Sujanto, et al., 1992)

During the dry season only a few wells can still produce water. One of them is the well that located at RT $36 \mathrm{RW} 7$ at the coordinates of 8014 ' $32.53^{\prime}$ ' $\mathrm{LU}$ and $112039^{\prime} 23.95$ 'BT. Based on the field study, the well was passed by an underground river. In addition, at the western of the village there are two sources of springs that appear on the surface. From this phenomenon we can trace and find the distribution of underground water around this location. The existence of groundwater reserves can later be used as recommendations in drilling well.

Several methods are used to identify the subsurface layer. They are geological methods, gravity methods, magnetic methods, seismic methods, and geoelectric methods. From all that methods, the geoelectric method is the most commonly used method and the results are good (Sajeena et al., 2014; Onojasun, 2015), The geoelectric method consists of resistivity, selfpotential and inducted polarization.

We choose the Self Potential method to estimate initial information about subsurface structures based on potential value distribution. Self Potential method can detect one source of natural potential, namely electrokinetic potential that arises from the flow of fluid, that is ground water through a porous pot medium (Telford, 1990; Ishido et al., 2010). The use of the Self potential 
method includes detecting metal minerals (Adeyemi et al., 2006), geothermal reservoirs (Ishido et al., 2010), underground water and other (Satou et al., 2004). The our reason to use the self-potential method (SP) is because this method is quite effective, efficient, and very affordable.

Research using the Self Potential method had previously been carried out by Adi Susilo, et al in 2017 to map the underground river flow in the karst region. From that study, there was an underground river water flow from the North to the Southwest and it was possible to end up at the Lesti River in the northern part of the study site (Susilo et al., 2017).

The purpose of this study is to identify the distribution of groundwater reserves in the Wonorejo Village, Malang District by using a Self-Potential method. The results of this study are expected to provide recommendations for digging wells at points that have the potential for having groundwater reserves or through underground rivers.

\section{METHODS}

Self potential (SP) is a potential difference that occurs naturally between points on the surface of the land. The self potential (SP) method is classified as a passive method, by measuring the natural static stress at the ground level (Revil \& Hubbard, 2009; Sharma, 1997). Potential differences are produced in the earth or rocks that are organized by nature and human activities. Natural potential occurs due to imbalance or differences in materials, near electrolyte solutions of different concentrations and due to fluid flow below the surface. Selfpotential can also arise due to electrochemical and mechanical activity on earth. The controlling factor for this activity is groundwater.

\section{Data Acquisition}

The field survey was conducted for the first time to determine the geological conditions of the research location and to determine field measurements to make it easier to collect data in the field (Susilo et al., 2013).

Measurements were done on 26-29 August 2017 in Druju Village Sumbermanjing Wetan Subdistrict, Malang Regency. Data acquisition is done using digital millivoltmeter. The electrodes used are formed from conductive metal dipped in a solution of CuSO4, ZnSO4 and so on. The solution and metal are packed into a pot-shaped electrode and have porous that is made of earthenware. The use of porous pots is expected that the solution will seep slowly.

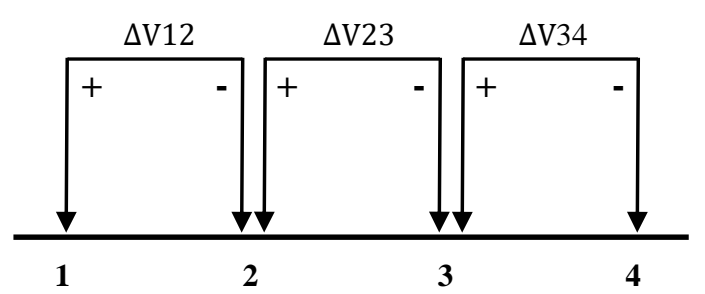

Figure 2. Leapfrog configuration data acquisition technique

The Figure 2 shows that " $\Delta \mathrm{V} 12$ " is the potential difference between point 1 and 2. " $\triangle \mathrm{V} 23$ " is the potential difference between point 2 and 3 and so on. The sign (+) is the polarity of the positive electrode and the sign (-) is the polarity of the negative electrode. The Data collection techniques used the leapfrog configuration by placing two electrodes at the same distance on all measurements. The positive electrode at the first point of measurement is moved into a negative electrode on the next measurement and so on, and when the research ends, it must be measured again at the first point of measurement to get the correction. 
The total of measurement points in the study area is 105 points with a length track of about 2 kilometers and a width of 400 meters, while the average distance between point is 100 meters and the distance between porous pots is 10 meters. To obtain an iso-potential distribution map at the research location, the Self-Potential measurement points are attempted to be distributed in regular grids form or trajectories (Revil \& Hubbard, 2009).

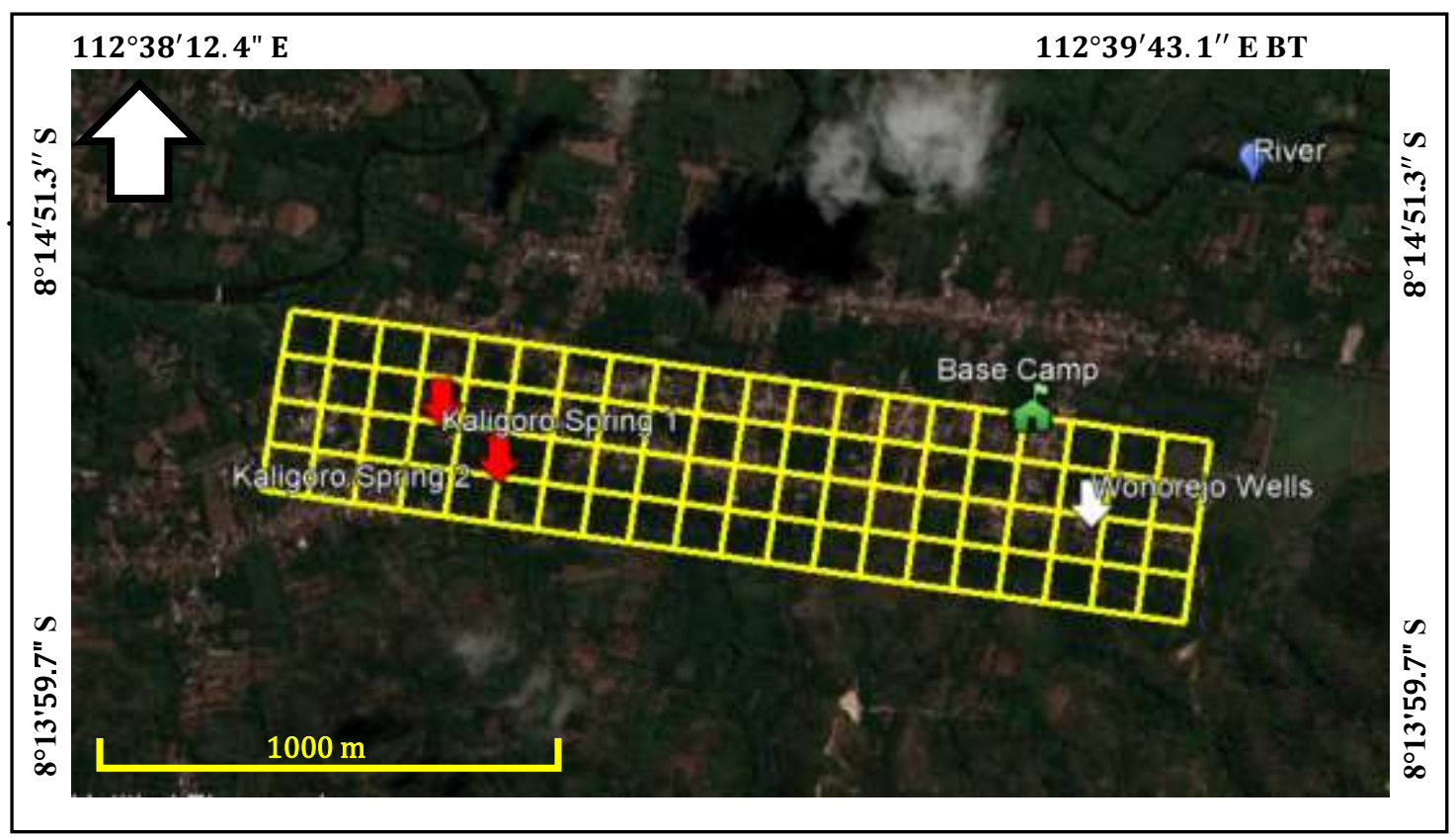

Figure 3. Self Potential Method (SP) Data Collection Survey Design

Tool calibration was carried out before the study in order to obtain better field data. Tool Calibration can be done by measuring the potential difference on the porous pot electrode that is placed on the water with a distance of approximately $10 \mathrm{~cm}$. The potential difference values measured during calibration must be smaller or equal to 2 milliVoltIf the measured potential difference is greater than 2 milliVolt, it means that the porous pot is not clean or leaky. So that, the electrode (porous pot) must be cleaned then filled with a new $\mathrm{CuSO} 4$ solution and the same concentration in both electrodes.

\section{Data Processing}

Data processing was carried out to determine the subsurface conditions of the research location by performing subsurface modeling based on physical parameters. The physical parameter used in this study is the potential difference value of rocks. The software used in this research is Microsoft Excell and Surfer 13.

\section{Interpretation}

Interpretation is the final process in this study, the interpretation was carried out at all data collection points to determine subsurface lithology and determine the distribution pattern of groundwater. Interpretation of the Self Potential method is carried out on data that has been corrected and then interpreted qualitatively. Data interpretation of the Self Potential method is carried out by interpreting the isopotential contour map generated by the Surfer 13 software according to the measured parameters. The interpretation needs to be supported by additional data such as geological 
data on the physical conditions of the research location.

\section{RESULTS AND DISCUSSION}

Based on the geological map of the Turen sheet that was made by Sujanto et al., In 1992, the study area was in the Wonosari formation, where the wonosari formation was composed of 3 rock types which is composed of limestone, sandy marl and claystone intercalations (Sujanto et al., 1992). The measurement results of the Self Potential method are electric potential quantities form with $\mathrm{mV}$ units which are then interpreted qualitatively using surfer 13 software and supporting data on geological maps. Figure 4 shows the result of an isopotential contour map interpretation that shows the lithology of the soil surface of the research area as follows:

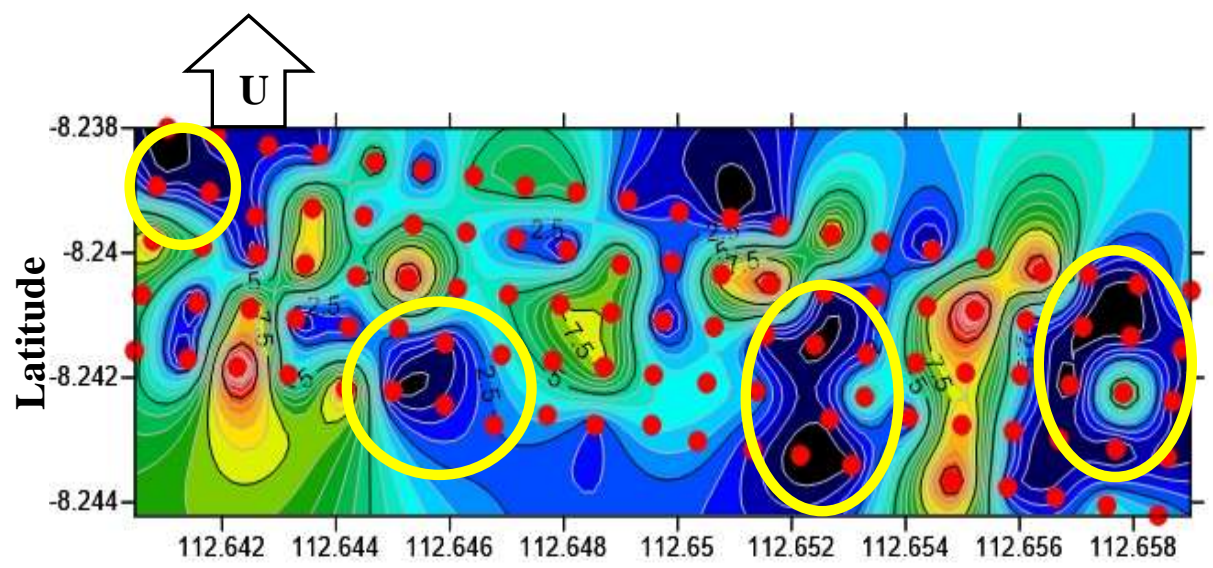

Longitude

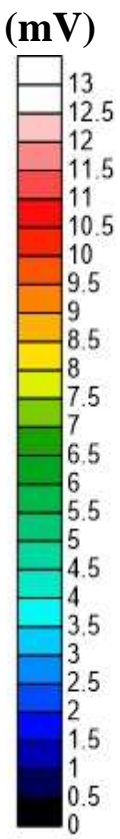

Figure 4. Isopotential Contour Map

The isopotential contour map at Figure 4 shows that the interpretation of several anomalies that is found at the study site. The potential value of the isopotential contour map ranges about $0 \mathrm{mV}$ to 13.5 $\mathrm{mV}$. The black colour at contour map shows a low potential self value with a value of $0 \mathrm{mV}$ to $1 \mathrm{mV}$. We consider this pattern as an area that has the potential to be traversed by water as a study that has been conducted by (Jinadasa \& de Silva, 2009; susilo et al., 2017) shows that low resistivity value can be interpreted as underground water and it is supported by a potential value of low or negative Self Potential, so that in this study the same conclusion can be produced (Susilo, et al., 2017).

Figure 4. shows that the area with the lowest anomaly (black color) is found at four areas. The first area is in the easternmost region (the rightmost yellow circle) which shows the presence of a black canal and incidentally in that area there is a well that is passed by an underground river. The middle part (the second yellow circle from the right) also has an area with quite low anomalous value, in this area it is looks like the water reserves are quite large. At the west area (the second yellow circle from the left) is found again an area with a low 
anomaly, which is as the emergence of water source on the ground. The last area with a low anomaly is found at the tip of the northwest corner (the far left yellow circle), this might be because the area is at the river bank, so it is possible that the area was passsed by water before it empties into the river. The area with the lowest potential value can be used as a reference in making wells, because the area may have sufficient groundwater reserves.

The isopotential contour map in Figure 4 shows the absence of an interconnected low potential value area (shown in black separately). This indicates that the possibility of groundwater distribution in this research area is not in one line/flow. However, it is possible that in areas outside the research location, groundwater flow is in one lane. Thus, to prove this assumption it is necessary to carry out further research in a wider area and the use of other geophysical methods to obtain more varied subsurface information. The figure 5 shows the result combination of isopotential contour maps with google earth.

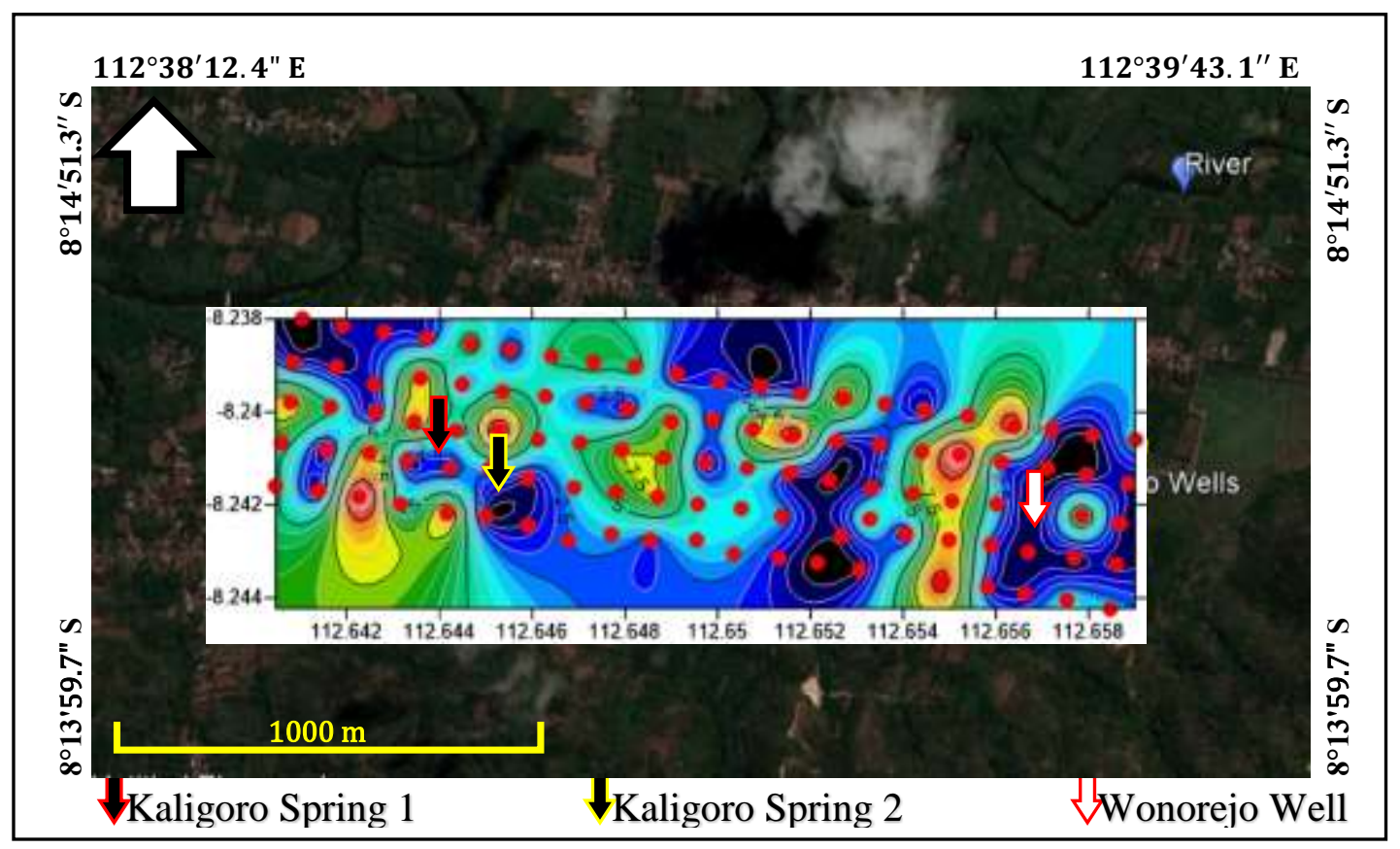

Figure 5. Overlay of SP Countours, Line Resistivity and Google Earth

\section{CONCLUSION}

The value of electric potential that is detected between $0-13.5 \mathrm{mV}$, where the lowest potential value $(0-1 \mathrm{mV})$ is an indication of the potential distribution of groundwater reserves. The possibility of groundwater distribution in this research area is not in one line / flow.

\section{ACKNOWLEDGEMENT}

The author would like to thank to the residents of the Druju village, Sumbermanjing Wetan sub-district, who had given permission to do this study and thankful to all parties who involved in conducting this research. 


\section{REFERENCES}

Malang District Disaster Management Agency. (2015) Disaster Inventory of Disaster Management Agency in Malang Regency. http://bpbd.malangkab.go.id/source/2 /INVT\%20BENCANA/Inventaris\%20 Bencana\%202015\%20(no).xls, 8 March 2018.

Adeyemi, A. A., Idornigie, A.I., Olorunfemi, M. O. (2006). Spontaneous Potential and Electrical Resistivity Response Modelling for a Thick Conductor. Journal of Applied Sciences Research, 2 (10), 691-702.

Fetter, C. W., (1994). Applied Hydrogeology. Amerika, Prentice Hall.

Ford., D. and Williams P. (2007) Karst Hydrogeology and Geomorphology. England, John Wiley and Sons Ltd.

Ishido, T., Nishi, Y., and Pritchett, J. W. (2010). Application of SelfPotential Measurements to Geothermal Reservoir Engineering: Characterization of Fractured Reservoirs. Proceedings, Thirty-Fifth Workshop on Geothermal Reservoir Engineering Stanford University, Stanford, California, February 1-3, 2010.

Jinadasa, S. U. P., and R. P de Silva. (2009). Resistivity Imaging and Self Potential Application In Groundwater Investigation In Hard Crystalline Rocks. Journal of the National Science Foundation of Sri Langka, 37 (1), pp. 23-32. http://doi.org/10.4038/jnsfsr.v37i1 .454

Onojasun, O. E. (2015), Delineating Groundwater Contaminant Plums Using Self Potential Surveying Methtod in Perth Area, Australia. International Journal of Scientific and Technology Research. 4 (11). pp. 55-59.

Revil, A., Hubbard, S., (2009). SelfPotential and Induced

Polarization: Geophysical Tools to Map Flowpaths and monitor Contaminant Plumes. Department of Geophysics, Colorado Schools of Mines, U.S.

Sajeena S., Abdul Hakim V. M. and Kurien E. K. (2014). Identification of Groundwater Prospective Zones Using Geoelectrical and Electromagnetics Surveys, International Journal of Engineering Inventions, 3 (6), 1721.

Satou, S., Shimada, J., Goto, T. N. (2004). Use of Self-potential (SP) Method to Understand the Regional Groundwater flow System. Poster. Kumamoto University. Japan.

Sharma, P. V. (1997). Environmental and Engineering Geophysics. Cambridge University Press, Cambridge.

Sujanto, Hadisantono R., Kusnama, Chaniago, R. and Baharuddin, R. (1992). Geological Map of The Turen Quadrangle, East Java, Geological Research and Development Center, Bandung.

Susilo, A., Sunaryo, Sutanhaji, A.T., Fitriah, F., Hasan, M. F. R. (2017). Identification of Underground River Flow in Karst Area Using Geoelectric and Self-Potential Methods in Druju Region, Southern Malang, Indonesia. International Journal of Applied Engineering Research, 12 (21). pp. 10731-10738. Research India Publications.

Susilo, A., Sunaryo, Wasis. (2013). Subsurface Structure Prediction of Railroad Tunnel in Malang. Indonesia Based on Dipole-Dipole Geoelectrical Method. Journal of 
Applied Research on Civil Engineering and Environment (ARCEE) VOL. 01 NO. 01, August 2019

Traffic and Logistics Engineering, 1 (2). pp 238-242.

https://doi.org/10.12720/jtle.1.2.2

$38-242$

Telford, W. M. (1990). Applied

Geophysics. Second Edition,

Cambridge University. 